\title{
Multi-species habitat models highlight the key importance of flooded reedbeds for inland wetland birds: implications for management and conservation
}

\author{
Michelangelo Morganti ${ }^{1,7^{*}}$, Milo Manica ${ }^{1}$, Giuseppe Bogliani ${ }^{1}$, Marco Gustin ${ }^{2}$, Federica Luoni ${ }^{2}$, Paolo Trotti ${ }^{3}$,
} Vincenzo Perin ${ }^{4}$ and Mattia Brambilla ${ }^{5,6}$

\begin{abstract}
Background: Inland wetlands are crucial for biodiversity conservation, especially in highly-urbanized landscapes. In the European Union, many wetlands are included in the EU 'Natura 2000' network, the main tool for biodiversity conservation over the continent, which requires the development of site-specific management plans. Clear and feasible recommendations are necessary to provide site managers with effective tools for the maintenance of biodiversity in these unstable environments. Birds are excellent umbrella species, therefore a management targeted at increasing habitat suitability for focal bird species would likely benefit broader wetland biological communities.
\end{abstract}

Methods: During spring-summer 2017, we collected presence/absence data for 10 bird species of conservation interest at a site scale for 21 Natura 2000 sites. We also carried out a point count survey to detect presence/absence of four reedbed-dwelling species at 75 points. At the site level, we estimated landscape characteristics from regional GISlayers, whereas fine-scaled habitat composition was recorded on the field within a $100 \mathrm{~m}$-buffer around the 75 points. We analysed the effect of the extent of different habitats on species' occurrence probability by means of multi-species binomial multivariate adaptive regression splines (MARS) at both scales. We also run species-specific MARS models to compare their performance with those of multi-species models.

Results: At the site scale, the extent of the reedbeds/mires was positively associated with the occurrence of all species of conservation concern. At the point-count scale, reedbed extent positively predicted species' occurrence, but only in presence of patches of clear shallow water. Species-specific MARS models showed qualitatively similar results for some species, but generally were outperformed by multi-species ones.

Conclusions: Multi-species MARS models confirmed to be an efficient tool in disclosing species-habitat relationships even for set of species including scarce taxa and when only short-term monitoring data are available. In terms of conservation measures, our findings stress the importance of Phragmites australis reedbed as a key habitat for avian biodiversity, but only when it is flooded and interspersed with scattered patches of open water. The preservation of wide (> 100/150 ha) and flooded reedbeds structured in spots of no less than 2 ha emerges as the main conservation measure for the long-term conservation of the threatened avifauna of inland pre-Alpine wetlands.

Keywords: Multivariate adaptive regression spline, Natura 2000, Pre-Alpine belt, Species-habitat relationship, Umbrella species, Urbanized landscape

\footnotetext{
*Correspondence: michelangelomorganti@gmail.com

${ }^{1}$ Department of Earth and Environmental Sciences, University of Pavia,

Via A, Ferrata 9, 27100 Pavia, Italy

Full list of author information is available at the end of the article
} 


\section{Background}

Wetlands represent a small percentage of the emerged land surface (4-9\%; Mitsch and Gosselink 2000; Zedler and Kercher 2005) but deliver the $40 \%$ of global ecosystem services (Zedler and Kercher 2005), including those of water supply, resilience to climate change and, particularly, those related to biodiversity conservation (Ramsar Convention Secretariat 2006). The long-term persistence of wetlands is particularly threatened in highly anthropized areas and in those of rapid demographic increment since water drainage for civil uses eventually shrinks the water availability for natural environments (Prigent et al. 2012). Therefore, the growth of the human population is probably the main cause of the alarming contraction of wetland surface at a global scale, estimated at $61-70 \%$ in the twentieth century (Gardner et al. 2015). The most representative wetland habitats are protected in Europe since 1992, when the European Union defined a list of 'habitats of priority conservation interest' (92/43/CEE-'Habitats Directive'). Thanks to the 'Habitats Directive', a vast network of protected areas (particularly representative for wetlands) was then established based on the local occurrence of habitats included in this list, as well as on the occurrence of bird species listed in the Annex I of the 'Birds Directive' (2009/147/EC). The network of protected areas that was established on the basis of the two aforementioned directives takes the name of 'Natura 2000' and nowadays includes many of the most important European wetlands and is made of two types of protected areas: Sites of Community Importance (SCIs; now Special Areas of Conservation, SACs), established on the occurrence of habitats listed in the 'Habitat Directive' Annex I, and Special Protection Areas (SPAs), which host important populations of threatened bird species listed in the 'Birds Directive' Annex I.

Overall, Natura 2000 proved to be an efficient tool to preserve biodiversity in Europe (Trochet and Schmeller 2013); however, a simple protection status is not enough for wetlands, because these are naturally unstable environments, which, especially in the absence of natural, dynamic processes, need an active management to ensure their long-term survival and efficiency as supplier of ecosystem services (Zedler and Kercher 2005). However, the management of protected wetlands targeted at biodiversity conservation can be tremendously challenging: the fine control of the waterbody hydrology, on which wetland characteristics depend, should be ideally associated to specific management measures for each of the different habitats occurring within the wetland (i.e. Weller 1994; Russo 2008; Gray et al. 2013; Meli et al. 2014). Management complications are exacerbated by the very scarce resources that local managers usually can allocate to both preliminary surveys and successive practical interventions.

Wetland-dwelling birds are suffering worldwide population declines (Wetland International 2018), associated to the progressive reduction of the wetland surface (Wang et al. 2018). Oscillations in abundance and occurrence of wetland birds, either estimated at the single species or at the community scale, have been shown to reflect environmental variation of their habitat over both short- and long-term periods (e.g. Almaraz and Amat 2004; Martínez-Fernández et al. 2005; Rendón et al. 2008; Fasola et al. 2010). Furthermore, many wetland bird species occupy high ranks in the trophic chain, so that their abundance and occurrence generally relate to those of lower-ranking organisms (e.g. Matsinos and Wolf 2003; Burger and Eichhorst 2005, but see in contrast Guareschi et al. 2015). Overall, with the due cautions, the occurrence of focal species of wetland birds can be safely used as an indicator of the general ecological status of a given area (Cable et al. 1989; Amat and Green 2010). Therefore, considering management issues and the critical status of several wetland sites and wetland species, coupled with a widespread lack of resources, there is an urgent need for working flows and procedures that allow the definition of concrete management indications based on relatively short-termed and affordable survey protocols. Such tools are urgently required to concretely foster the conservation of wetlands, preventing the loss of their key features and preserving the threatened species and communities they harbour. Birds are particularly suited as model organisms for this task, considering both their ecology and the concerning status shown by several wetland species.

We used bird-occurrence data collected during surveys carried out in a single breeding season to identify key management recommendations for preserving wetland biodiversity. We used both single-species and multi-species modelling of habitat requirements and evaluated their potential use as tools to define practical management indications even based on a single-season dataset. Specifically, the aims of this study were to (1) identify the landscape-scale variables affecting the biotope-level occurrence of bird species of conservation interest; (2) identify, at a finer scale, which habitat variables are associated with the occurrence of a set of target reedbed-dwelling species. Furthermore, the ultimate objective of this study was (3) to obtain practical management recommendations for the conservation of bird communities and populations in inland wetlands of the pre-Alpine belt. 


\section{Methods}

\section{Study areas}

We studied the bird communities of inland wetlands located in the pre-Alpine belt of Lombardy Region (Northern Italy, Fig. 1), one of the most densely populated area of Europe, with a mean population density of 421 people $/ \mathrm{km}^{2}$ (ISTAT 2018). Inland wetlands of Lombardy are severely threatened by anthropic pressure and measures to foster their long-term conservation should be a priority for regional and national governments, also considering the EU requirements. Our study was carried out in 21 inland wetlands within the 'Natura 2000' network (Fig. 1, 'study sites' thereafter). Most of the sites are rather small wetlands (mean extension in ha \pm SD $371.58 \pm 441.56$; $\min 20.23$, $\max 1610.64$ ) of post-glacial origin (sites 4-14 and 19-20 in Fig. 1), while others originate as shallow water areas along major rivers (i.e. river Adda, sites 16-18) or lakes (i.e. Lake Maggiore, sites 1-3; Como Lake site 15). The study sites are scattered over an area of $\sim 7800 \mathrm{~km}^{2}$, ranging between $46^{\circ} 12^{\prime}-45^{\circ} 38^{\prime} \mathrm{N}$ and $8^{\circ} 36^{\prime}-10^{\circ} 01^{\prime} \mathrm{E}$ (Fig. 1), at an average elevation of 257.95 $( \pm 82.89 \mathrm{SD}) \mathrm{m}$ a.s.l. (range $171-537)$. The climate is temperate continental, with a mean annual temperature of
$11.1{ }^{\circ} \mathrm{C}$ and mean annual precipitation of $1236 \mathrm{~mm}$ (values referred to Montorfano Lake, nearly occupying the mid-point of the study area, source: Merkel 2017). The habitat of the study areas is mainly characterised by the occurrence of patches of Phragmites australis, in some cases forming wide continuous reedbeds up to 290 ha (site 5, Fig. 1), but generally reduced to thin strips of a few meters of width bordering open water extents. Together with the reedbeds, the study areas host patches of wetland habitats protected by the European Union's Habitat Directive as the "alluvial forests with Alnus glutinosa and Fraxinus excelsior (Alno-Padion, Alnion incanae, Salicion albae)" (EU code: 91E0) and the "Natural eutrophic lakes with Magnopotamion or Hydrocharition-type vegetation" (EU code: E3150).

\section{Target species}

We performed our study by surveying different sets of species at two different spatial scales, i.e. the 'study site' scale (with Natura 2000 sites being the sampling units, $n=21$ ), and the 'point count' scale (with sampling points surveyed during point counts as sampling units, $n=75$ ). At the site scale, we checked the occurrence as

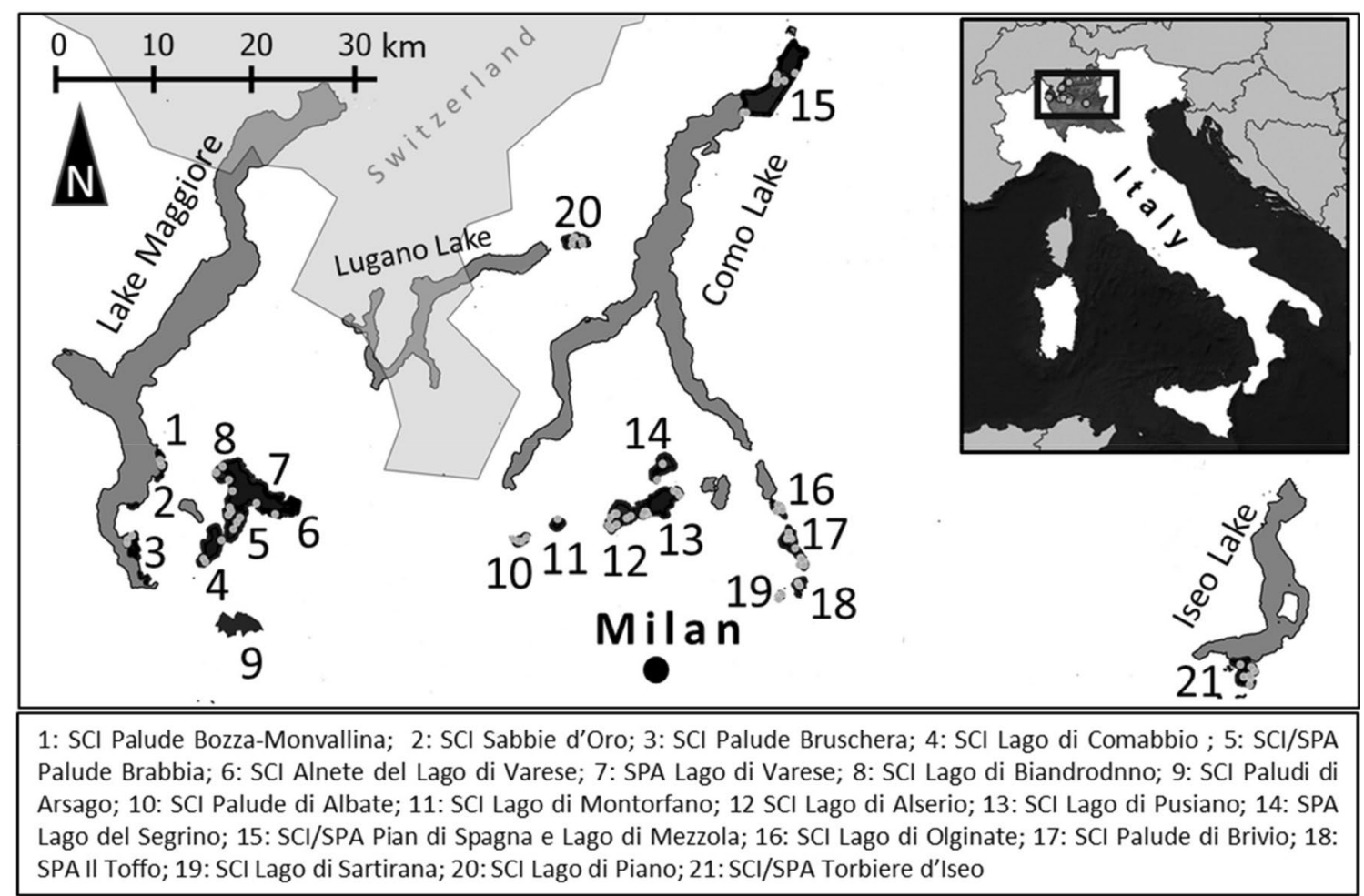

Fig. 1 Maps of the study area. Distribution of the 21 Natura 2000 sites surveyed during the study. The location of the point surveyed by means of point counts ( $n=75$, grey dots) within each site is also shown. The main lakes of the area are shown. Names of the sites are indicated in the below box, along with the indication of protection status (either Sites of Community Importante 'SCI'/Special Area of Conservation 'SAC'sensu EU Directive 92/43, or Special Protection Area'SPA' sensu EU Directive 2009/147/EC) 
breeding taxa of 10 species of conservation priority in the EU (i.e. included in the Annex I of the Birds Directive) and known to breed in some of the target sites: Western Marsh Harrier (Circus aeruginosus), Purple Heron (Ardea purpurea), Ferruginous Duck (Aythya nyroca), Kingfisher (Alcedo atthis), Black-crowned Night Heron (Nycticorax nycticorax), Little Bittern (Ixobrychus minutus), Black Kite (Milvus migrans), European Honey Buzzard (Pernis apivorus), Black Woodpecker (Dryocopus martius) and Lesser Spotted Woodpecker (Dendrocopos minor; the last not included in Annex I of the Birds Directive but of conservation concern at the local scale). We also checked for the occurrence of further three species listed in Annex I of the Birds Directive, but these eventually resulted completely absent (i.e. Moustached Warbler Acrocephalus melanopogon) or too scarce to be analysed in the study (Little Crake Porzana parva and Spotted Crake Porzana porzana occurred with only 1-2 pairs in the entire study area).

At the point count scale, we checked the occurrence of four bird species, not listed in the Annex I of the Birds Directive: Eurasian Reed Warbler (Acrocephalus scirpaceus, referred to as Reed Warbler hereafter in the text), Marsh Warbler (Acrocephalus palustris), Great Reed Warbler (Acrocephalus arundinaceus), passerines belonging to Acrocephalidae; Water Rail (Rallus aquaticus), belonging to Rallidae. The three passerines are insectivorous, long-distance migrants with diurnal habits and all breed in the reedbed, where they occur along a habitat gradient, with Great Reed Warbler occupying permanently flooded and monospecific reedbeds, and with Marsh Warbler at the other end of the gradient, inhabiting drier reedbeds mixed with bushes (Cramp and Simmons 1998; Kennerley and Pearson 2010). The Water Rail is a mainly nocturnal bird, which feeds on invertebrates found in the mud (Cramp and Simmons 1998) and yearround occurring in the area, although the migratory behaviour of the local populations is still poorly known. Overall, the habitat requirements of these four species taken together represent fairly well the broader spectrum of ecological niches occurring in reedbeds. Therefore, their presence can be taken as an indicator of the overall ecological status of a reedbed (see also Brambilla and Jenkins 2009; Mortelliti et al. 2012).

\section{Environmental variables}

Environmental variables were collected at the two different spatial scales of Natura 2000 sites and point counts respectively.

At the Natura 2000 sites scale, we estimated landcover within each study site, thanks to a land-use/landcover (LULC) map available from Lombardy Region and updated to 2015 (DUSAF 2015; resolution 1:10,000).
Even if this LULC map, based on photointerpretation, is very accurate and updated, we field-validated the boundaries of the habitat types and manually corrected them when needed in QGis (v 2.4.0, Quantum GIS Development Core Team 2018). Fifty-two LULC categories were included in our study areas: we then merged them into 9 habitat categories (see Additional file 1: Table S1 for the complete list of original habitat types): (1) 'reedbeds/mires' (mainly reedbeds of $P$. australis, but including mires and Magnocaricetum assemblages); (2) 'inland open waters' (natural and artificial ones); (3) 'non-vegetated areas' (including buildings); (4) 'arable lands'; (5) 'meadows'; (6) 'riparian vegetation' (low shrubby vegetation, at least occasionally flooded); (7) 'transitional shrubland' (high shrubs); (8) 'deciduous woods' (mainly Salix alba and A. glutinosa forest patches); (9) 'wood crops' (poplar plantations, orchards).

At the point count scale, we mapped the habitat composition within a $100 \mathrm{~m}$-buffer from each point (measured in QGis). Successively, we estimated the proportion of each habitat type within the buffer and eventually converted this proportion into an extent of habitat cover (ha). At this step, we considered 8 habitat categories: Open shallow water; $P$. australis reedbed; trees $(>5 \mathrm{mt}$ height); shrubs (<5 mt); meadows (<1 mt); Magnocaricetum complex (typical wetland assemblages of tall grasses, up to $1.5 \mathrm{~m}$, dominated by Carex spp., mostly C. elata, C. pendula and C. acuta within the study area); bare soil; other LULC types. Furthermore, since each point was visited for the environmental survey at least twice in the season, we added a categorical variable indicating if the reedbed fraction of the buffer was permanently inundated during the season (2), occasionally inundated (1), or permanently dry (0).

\section{Survey methods}

Surveys aimed to detect the species occurrence were also performed at the two different spatial scales of sites and point count, respectively (the sets of target species were mutually exclusive for the two spatial scales). To check the occurrence of the 10 species of conservation concerns, we followed the species-specific guidelines described in the 'Region Lombardy Plan for monitoring of avian species of Annex I' (Fondazione Lombardia per l'Ambiente 2015), adopting the adequate survey method for each target species and adapting the methodology to the two survey scales.

\section{Natura 2000 site survey scale}

At the site scale, the presence/absence of Lesser-spotted and Black Woodpecker was assessed by means of linear transects carried out along existing pathways: within each wetland, an observer walked at a slow pace along 
the transect in early morning in March-April, when woodpeckers' territorial activity peaks (Cramp and Simmons 1998). The presence/absence of Marsh Harrier, Purple Heron, Night Heron, Black Kite and Honey Buzzard was assessed by means of morning observation sessions (duration: $2-4 \mathrm{~h}$ according to site characteristics), starting $1 \mathrm{~h}$ after sunrise, in May-June. Whenever possible, vantage points allowing a comprehensive view of the wetland were chosen for these observational sessions. Wood patches of the studied areas are often of limited extent, which makes easier-compared to other environmental contexts-to assess the occurrence of breeding tree-nesting raptors. Furthermore, to assess the occurrence as breeding species of Black Kite and Honey Buzzard, we also collected anecdotal observations from local birders that frequently visited the areas during our survey period. The occurrence of breeding Ferruginous Ducks was assessed in June, when chicks are still unable to fly, by means of observations from shorelines, coupled with kayak surveys of reedbed borders. Each site was monitored with the help of $20 \times 60$ telescopes and $10 \times 42$ binoculars, at least twice during the period. Opportunistic observations of Kingfishers, realized during the previously described dedicated sessions, were registered from March to June for all the surveyed sites and the presence of the species as a breeder was therefore established based on these data. The occurrence of breeding Little Bitterns was assessed in May-June, by means of nighttransects (from dusk to the 2-4 following hours) along the pathways closest to reedbeds, listening to males' territorial call.

\section{Point count survey scale}

At the point count scale, the occurrence of the three warblers species and of Water Rail was established by the means of point counts realized within $2 \mathrm{~h}$ after sunrise for warblers and at dusk (from $1 \mathrm{~h}$ prior to sunset to $2 \mathrm{~h}$ after) for Water Rail. Point counts have been reported as the most time-efficient way to estimate presence/absence and population density in elusive species (Sutherland et al. 2004). Census based on listening is the common method used to estimate presence/absence and abundance for reedbed-dwelling warbler species (i.e. Mortelliti et al. 2012; Sozio et al. 2012; Ceresa et al. 2016) and proved to be effective for rallids too (Polak 2005; Brambilla and Jenkins 2009; Jedlikowski et al. 2014). In the point counts aimed to detect water rail presence, we broadcast a registered call (1-min length) to stimulate a possible territorial response (e.g. Brambilla and Jenkins 2009), followed by $3 \mathrm{~min}$ of listening, again a 1-min stimulation and 3 further minutes of listening, for a total length of $8 \mathrm{~min}$. Increasing the duration of a listening point from the standard 5 min up to 8 should significantly enhance the detectability of elusive species, especially in censuses that are not maintained over consecutive years (Leu et al. 2017). The trace used for playback stimulation was built using the sounds records by Schultze and Dingler (2007). Point counts targeted at warblers were censused with no acoustic stimulation and lasted for $5 \mathrm{~min}$. Point counts for Water Rail were surveyed in the period 24 March-20 April, when the territorial activity of the species is at its peak in northern Italy (Brambilla and Rubolini 2004). Point counts focused on warblers were instead surveyed in the period 20 April-10 June, with two repetitions separated by at least 10 days.

\section{Statistical analyses}

We investigated the relationships between habitat variables (either collected at study site scale or at point count scale) and the probability of species occurrence by means of multivariate adaptive regression splines (MARS models). MARS is a non-parametric, machine-learning technique (Friedman 1991; Hastie et al. 2009) that well suits to investigate non-linear relationships between habitat features and occurrence (Elith and Leathwick 2007). Due to its effectiveness and flexibility, the use of MARS models is growing, and it has been recently applied in several studies based on survey data, analogous to those collected in the current study (e.g. Heinanen and von Numers 2009; Brambilla and Gobbi 2014; Brambilla and Pedrini 2016; Assandri et al. 2017). MARS models allow for multi-response tests, thus giving the opportunity to explore which factors have the main importance in determining species occurrence over an entire set of species, which are analysed at once. This MARS feature is particularly interesting for our set of data since some of our target species occurred at low frequency, and multiresponse models have been shown to outperform singlespecies models for scarce taxa (Elith and Leathwick 2007; Brambilla and Gobbi 2014; Assandri et al. 2017). The core result of the final multi-response model is, therefore, the selection of a set of habitat variables that are likely important for all the species; at the same time, multi-response models individually describe the effect of each habitat variable on the occurrence probability of each species.

We fitted MARS models with the earth package, version 3.2-1 (http://cran.rproject. org/web/packages/earth/ index.html), in R 3.1.2 (R Development Core Team 2018), using a binomial distribution of the response variable (Milborrow 2011a). We used the following settings for model selection: threshold $=0.01$, penalty $=3$. In all the cases, we tested models both allowing for the possibility of interaction between two variables (two-way interaction) and excluding the possibility of variable interaction (additive model; degree of interactions $=1$, no interaction allowed among variables). We evaluated the variable 
importance by means of the evimp command (Milborrow 2011a; Brambilla et al. 2013; Jedlikowski et al. 2014). The evimp estimates variable importance in MARS models reporting (1) the number of models in which, after the pruning pass, is included a given variable; (2) the change in the residual sum of squares (RSS), scaled to 100 , among each subset and the previous one thus indicating the change in the proportion of not-explained variance among the two models; (3) the generalized cross validation $(\mathrm{GCV})$ of each model, which considers the change in the GCV once the reference variable is entered or removed from the model. GCV is calculated using the penalty argument and scaled to 100 (Milborrow 2011a). The plotmo package version 1.3-1 (http:// cran.r-project.org/web/packages/plotmo/index.html) was used to plot the fitted functions (Milborrow 2011b). Results obtained with machine-learning methods are robust to collinearity in the set of the predictors (Garg and Tai 2013), but we applied a conservative approach and checked by means of VIF (variance inflation factor) that the set of the habitat variables presented a small degree of autocorrelation (VIF $<3$; Salmerón Gómez et al. 2016). At this step, we found collinearity in both set of predictors and we therefore excluded the extent of meadows and those of transitional shrubland areas from further analyses at the site-level scale (max VIF value after exclusion: 2.01), and the extent of tree cover from the predictors used in the analyses at the point count scale (max VIF value after exclusion: 2.08). Based on these predictor sets, we run two multi-response MARS models, one to explore the habitat variables predicting the probability of occurrence of the target species at the site level, and a second one exploring the analogous relation at the point count level. For the point count scale, we also run single-species MARS models to compare their performance with those of multi-response ones. We did not run single-species models for data collected at the site level, since the sample size was considered to be too reduced to have reliable results, as some preliminary tests confirmed (details not shown).

Graphically, the output of MARS models is presented in form of plots representing with a spline the non-linear function linking the extension of a given habitat type and the occurrence probability of a given taxon. In most cases, these functions have a threshold point: above or below this value the spline flattens, thus indicating that further increases (or decreases) in habitat extension has no longer effects on occurrence probability. The exact values of this threshold point, if present, are indicated in the output generated with the summary function of the MARS models, and we took it as a threshold also for practical management recommendations.

\section{Results}

Factors determining species occurrence at the Natura 2000 sites scale

The multi-response MARS procedure selected a single predictor, the extension of 'reedbeds/mires' as positively affecting occurrence probability of the set of species considered at the scale of Natura 2000 wetlands sites (Table 1, Fig. 2). The threshold point in the MARS multi-response models was found at 23.00 ha for 'reedbeds/mires': sites containing less than 23 ha of this habitat types had almost null probability of occurrence for

Table 1 Results of MARS models exploring which habitat types predict the occurrence probability of species of conservation interest at the Natura 2000 sites scale $(n=21)$

\begin{tabular}{|c|c|c|c|c|c|c|c|}
\hline Type of model & Species & Selected variables & No. of subsets & GCV & RSS & $R^{2}$ & $\begin{array}{l}\text { Sites of occurrence } \\
\text { (total no. } \\
\text { of sites }=21 \text { ) }\end{array}$ \\
\hline \multirow[t]{11}{*}{ Multiresponse } & & Reedbeds/mires & 1 & 100 & 100 & & \\
\hline & Marsh Harrier & & & & & 0.50 & 4 \\
\hline & Purple Heron & & & & & 0.57 & 3 \\
\hline & Ferrouginous Duck & & & & & 0.08 & 4 \\
\hline & Kingfisher & & & & & 0.15 & 14 \\
\hline & Night Heron & & & & & 0.49 & 3 \\
\hline & Little Bittern & & & & & 0.08 & 14 \\
\hline & Black Kite & & & & & 0.20 & 11 \\
\hline & Honey Buzzard & & & & & 0.15 & 4 \\
\hline & Lesser-spotted Woodpecker & & & & & 0.02 & 8 \\
\hline & Black Woodpecker & & & & & 0.03 & 4 \\
\hline
\end{tabular}

The results of both multi-response and species-specific models are presented. No. of subsets: number of models generated by the pruning pass, which include a given variable; GCV: generalized cross-validation; RSS: decrease in the residual sum-of-square; $R^{2}$ : model's $R$ square. Sites of occurrence: number of sites in which the species was detected, out of 21 total surveyed sites 

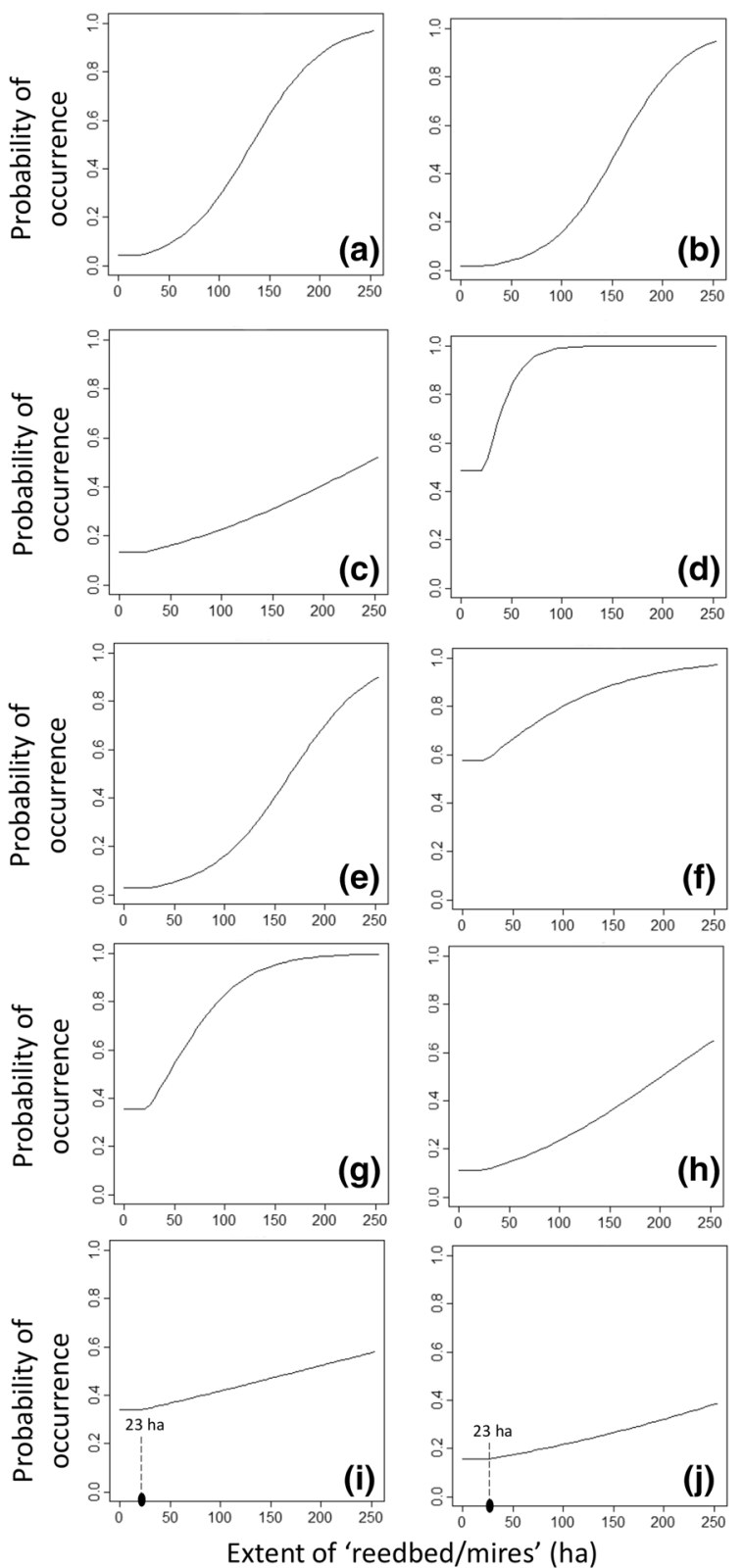

Fig. 2 Results of the MARS models run at the site scale. Graphical representation of the relationship modelled by means of multivariate adaptive regression splines (MARS), linking the occurrence probability of 10 species of conservation interest and to the extent (in ha) of the habitat 'reedbeds/mires' in 21 Natura 2000 wetlands of northern Italy. The graphs show the species-specific relationships as resulting from the multi-species model (see Table 1 and text for details). Dotted lines in the lower boxes indicate the position of the threshold value (unique for all the species) identified by MARS procedure. a Marsh Harrier; b Purple Heron; c Ferruginous Duck; d Kingfisher; e Night Heron; f Little Bittern; g Black Kite; $\mathbf{h}$ Honey Buzzard; i Lesser-spotted Woodpecker; $\mathbf{j}$ Black Woodpecker
3 species (Purple Heron, Marsh Harrier, Night Heron), very scarce $(<0.2)$ for Ferruginous Duck, Honey Buzzard and Black Woodpecker and scarce $(0.2<p<0.6)$ for the remnant species. Only in correspondence of very wide 'reedbeds/mires' ( 150 ha) extent, the occurrence probability for most species reached very high values $(>0.9)$, with the exception of the two woodpeckers. For the latter, occurrence probability remained lower than 0.6 even for extent above 250 ha (Fig. 2).

\section{Factors determining species occurrence at point-counts scale}

Multi-response models retained reedbed extent and extent of 'open shallow water' as the two variables explaining the occurrence probability in the four target species (Table 2, Fig. 3). For all species, reedbed cover within the $100 \mathrm{~m}$-buffer had a positive effect; the extent of open water also had a positive effect for all species apart Water Rail, which was less frequently observed with increasing size of the open water patches. The threshold point in the MARS multi-response models was established at 0.94 ha for open shallow water and at 1.73 for reedbed extent. In both cases, above the thresholds values the probability of occurrence reached a plateau (Fig. 3).

The single-species MARS models retained the 'reedbed' and the 'open water' predictors respectively in three and one cases (Table 2) but selected also other predictors. The presence of Magnocaricetum patches and the permanent flooding of the reedbed positively predict the occurrence of Great Reed Warbler, which was also negatively affected by the occurrence of bushes within the 100 m-buffer (Table 2). Marsh Warbler occurrence was still associated with reedbed extent, but also with bare terrain patches and other types of vegetation, although the two latter predictors had lower importance according to the relative GCV and RSS values (Table 2). No interaction term was retained by the selection process nor in single or multiple response models.

\section{Discussion}

Our findings confirm the efficiency of multi-response models in analysing the habitat features driving occurrence in a set of species including scarcely represented taxa in terms of prevalence or number of occurrences (Leathwick et al. 2006; Heinanen and von Numers 2009; Brambilla and Gobbi 2014; Brambilla and Pedrini 2016; Assandri et al. 2017). Furthermore, we found that multispecies modelling is well-suited to analyse occurrence dataset collected during a single breeding season, which 
Table 2 Results of MARS models exploring which habitat types predict the occurrence probability of reedbed species at the point count scale $(n=75)$

\begin{tabular}{|c|c|c|c|c|c|c|c|}
\hline Type of model & Species & Selected variables & No. of subsets & GCV & RSS & $R^{2}$ & $\begin{array}{l}\text { Points of occurrence } \\
\text { (total no. } \\
\text { of points }=75 \text { ) }\end{array}$ \\
\hline \multirow[t]{6}{*}{ Multiresponse } & & Reedbed & 2 & 100 & 100 & & \\
\hline & & Open water & 1 & 35.4 & 56.8 & & \\
\hline & Water Rail & & & & & 0.1 & 32 \\
\hline & Great Reed Warbler & & & & & 0.1 & 51 \\
\hline & Eurasian Reed Warbler & & & & & 0.3 & 51 \\
\hline & Marsh Warbler & & & & & 0.2 & 25 \\
\hline Specific & Water Rail & Reedbed & 1 & 100 & 100 & 0.1 & 32 \\
\hline \multirow[t]{3}{*}{ Specific } & Great Reed Warbler & Bushes & 2 & 100 & 100 & 0.2 & 51 \\
\hline & & Magnocarex & 1 & 40.2 & 55.6 & & \\
\hline & & Flooding status of the reedbed & 1 & 40.2 & 55.6 & & \\
\hline \multirow[t]{2}{*}{ Specific } & Eurasian Reed Warbler & Reedbed & 2 & 100 & 100 & 0.3 & 51 \\
\hline & & Open water & 1 & 65 & 65.5 & & \\
\hline \multirow[t]{3}{*}{ Specific } & Marsh Warbler & Reedbed & 3 & 100 & 100 & 0.3 & 25 \\
\hline & & Other types of vegetation & 2 & 37 & 62.5 & & \\
\hline & & Terrain & 1 & 11.5 & 40.8 & & \\
\hline
\end{tabular}

The results of both multi-response and species-specific models are presented. No. of subsets: number of models generated by the pruning pass, which include a given variable; GCV: generalized cross-validation; RSS: decrease in the residual sum-of-square; $R^{2}$ : model's $R$ square. Points of occurrence: number of points in which the species was detected, out of the 75 total points surveyed in the study

is the time-range commonly covered by survey programs funded as preliminary actions in conservation projects targeted at Natura 2000 management. Overall, our results suggest to rely on multi-species MARS modelling when analysing the habitat preference of a guild of species occupying the same environment, especially in presence of unevenly distributed taxa and based on a single-season dataset.

We are aware that establishing the Natura 2000 sites as sampling units to survey the occurrence of a set of species may have a limited biological meaning, since species might occur in the proximity of the protected sites in analogous habitats. However, the programs that give financial support to surveys and management (as in the case of the EU 'LIFE' projects) are generally structured to support actions in areas included in the Natura 2000 network, so testing whether data collected using this criterion can generate practical management indications is particularly interesting for management authorities. In addition, several Natura 2000 wetland sites in our study region are rather isolated from similar environments, being surrounded by heavily anthropized landscapes. The positive effect of the extent of reedbed/mires on occurrence probability in all the studied species, and over both spatial scale, may appear surprising, since some of the considered species do not use at all this type of environment (i.e. woodpeckers). However, the local occurrence of wide spots of reedbed implies the co-existence of a series of transitional habitats (i.e. from semi-urbanized areas to woodlands to wide reedbeds), which probably provide suitable habitats fulfilling the ecological requirements of the broad set of species we considered, from the most demanding and conservation-dependent ones, to the commonest wetland bird species. It should be noted that, while the category 'reedbed' in the analysis at the point count scale was strictly limited to pure $P$. australis beds, the reedbed/mires category used at the site scale was broader and included other types of habitats, commonly bordering the Phragmites patches, as isolated big trees (typically Salix alba in the study area) or small bush patches of Salix cinerea or A. glutinosa. Nevertheless, the fact that the relevance of 'reedbed' habitat overwhelmed those of other habitat categories in predicting the probability of occurrence is a result with relevant conservation implications. Indeed, stands of $P$. australis are not included in the EU list of 'natural habitat types of community interest whose conservation requires the designation of Special Areas of Conservation' (i.e. the Annex I, Habitat Directive 92/43/CEE). The rationale behind the apparently surprising decision of the EU commission to not consider this type of reedbed as of conservation interest is well comprehensible for at least two reasons: (1) stands of $P$. australis are very common in some areas of Europe (i.e. Northern Europe in particular, whereas they are scarcer in Mediterranean countries) and forcing member states to establish SCIs/SACs areas for each 

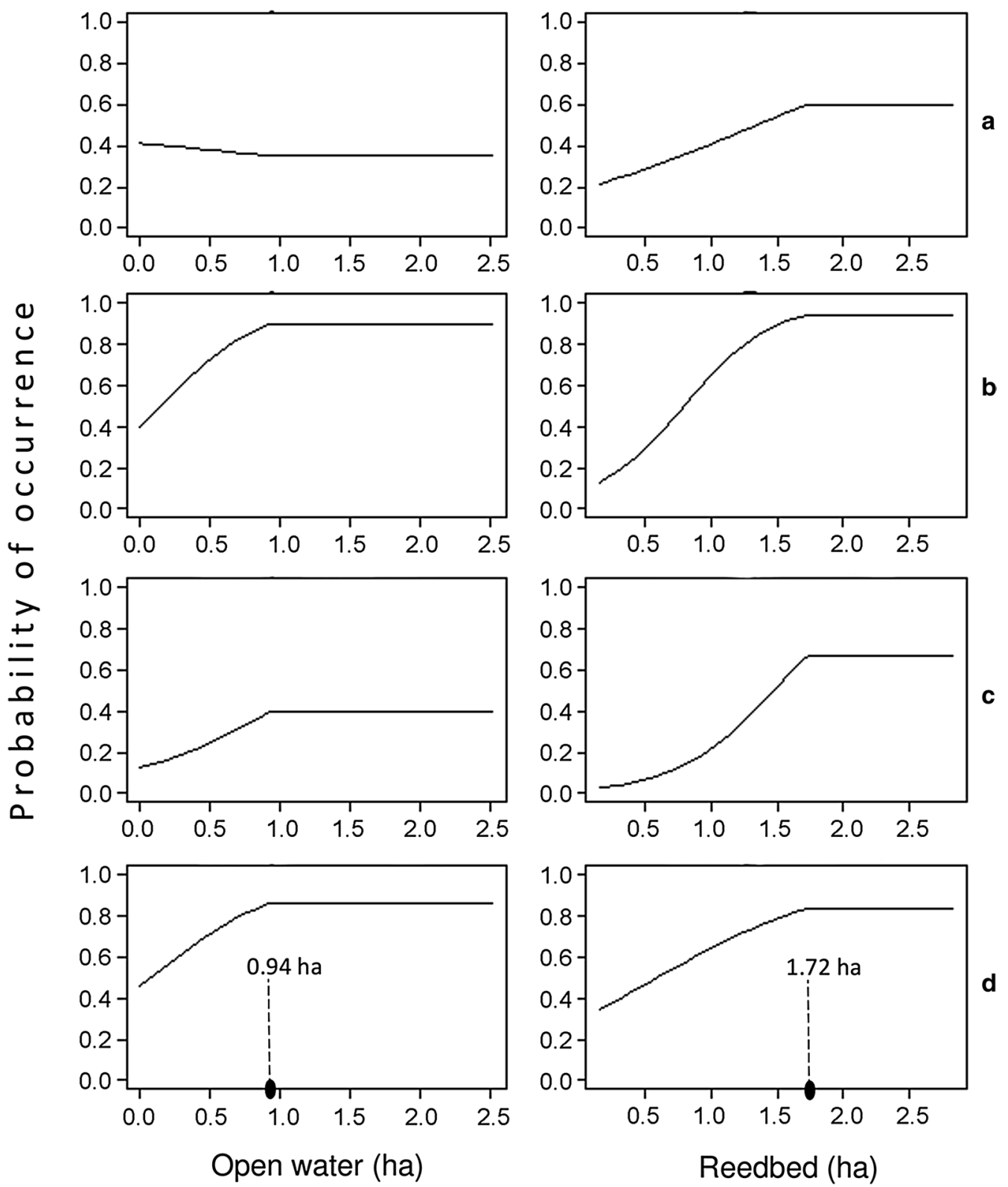

Fig. 3 Results of the MARS models run at the point count scale. Graphical representation of the relationships modelled by means of multivariate adaptive regression splines (MARS), linking the occurrence probability of 4 common species of wetland habitats and the extent in ha of the habitat categories 'open shallow water' and 'reedbed' in 75 count points. The graphs show the species-specific relationships as resulting from the multi-response model (see Table 2 and text for details). Dotted lines in the lower boxes indicate the position of the threshold value (one for each predictor but unique across species) identified by MARS procedure. a Water Rail; b Common Reed Warbler; c Marsh Warbler; $\mathbf{d}$ Great Reed Warbler

reedbed would not have been feasible; (2) $P$. australis is a plant with high colonization potential (Coops and van der Velde 1995; Fér and Hroudová 2009; SebastiánGonzález et al. 2012), and sub-specific strains may even have invasive behaviour out of their original range (i.e. Ward and Jacono 2009), so that generalized protection of the sites of occurrence of this species is unjustified. Furthermore, in a conservation perspective, it must be noticed that the simple occurrence of a reedbed is not enough for bird species to occur, as our own results also show. Among others, the extension of the reedbed fragment is commonly accepted as one of the features that most determine the suitability of a Phragmites stand for birds to reproduce in (e.g. Celada and Bogliani 1993; Barbraud et al. 2002; Mortelliti et al. 2012; Jedlikowski et al. 2014). In this work we found that, Natura 2000 sites 
having less than 23 ha of reedbed/mires extent have very low (>0.4) probability to be suitable for Little Bittern, Black Kite, Lesser-Spotted Woodpecker but almost null probability to host any of the other surveyed species. Above $23 \mathrm{ha}$, the relation among extension and occurrence probability takes considerable different shapes among species. Purple Heron, Marsh Harrier and Night Heron emerged as highly-demanding species, with high occurrence probabilities only in presence of very wide ( $>150 / 200$ ha) extent of reedbeds/mires. Other species maintain relatively low $(<0.6)$ occurrence probabilities even in presence of wide reedbeds/mires, suggesting that the extent of the reedbed/mire is probably only a concurrent factor in determining the occurrence (i.e. Ferruginous Duck) or that the occurrence of the species in this habitat type is marginal (i.e. woodpeckers). Eventually, the last group of species is composed by locally abundant species, whose occurrence probabilities strongly increase above the 23 ha (Little Bittern, Kingfisher, Honey Buzzard, Black Kite). While in the analyses at the Natura 2000 site level MARS models identified a 'bottom' threshold, multi-species MARS run on point-count data found a 'top' threshold, which is a value above which the occurrence probability no longer increases. Specifically, we found that the minimum size to maximize the occurrence probability of the four surveyed species is reached at reedbed patches of 1.72 ha, interdispersed with 0.74 ha open shallow water. Noticeably, 2 ha was also identified as the minimum fragment size for Phragmites patches to host viable populations of moths (Tscharntke 1992), and potentially of other preys of marshland birds. Indeed, the size of the Phragmites fragments is the main determinant of occurrence probability of marshland birds (Celada and Bogliani 1993). We stress that the simple-size evaluation does not control for the shape of the fragments. It has been described that the perimeter/area relation (i.e. a cue of the shape of the fragments) also contributes to determining the efficiency of a wetland in terms of ecosystem services (Tscharntke 1992; Van Meter and Basu 2015), even when taking into account the fact that landscape context may also concur in the suitability of Phragmites patches for breeding birds (Sozio et al. 2012). Additionally, the maintenance of ecotonal features in the reedbed patches has been described as a further aspect to be considered in management. As an example, a very fine-scaled study on Great Reed Warbler in Serbia, found that maintaining different water depth in the reedbed differently affected the survival probability of juveniles, males and females respectively (Méro et al. 2018). In the same study site, it has been observed that biggest, putatively dominant, Great Reed Warblers preferentially establish breeding territory in unmanaged (but flooded) portions of the reedbed, while smaller individuals mainly occupy portions of the reedbed in which winter harvesting and burning are practised (Méro et al. 2017). The maintenance of a range of different micro-habitats within a reedbed (i.e. portions of mature dense reedbed alternated to spots of early-successional sparse reedbed) is proposed as the best solution to preserve wetlands specialist avifauna by different authors (i.e. Barbraud et al. 2002; Beemster et al. 2010; Méro et al. 2018). To achieve the goals of maintaining a variety of micro-habitat within a reedbed, the management should be oriented to perform different practices (i.e. winter harvesting, controlled burns, non-intervention periods of established length) on different sectors of the reedbed (Russo 2008; Gray et al. 2013; Meli et al. 2014). This type of management probably has the greatest chance to optimize the functionality of the reedbed for a wide variety of avifauna (i.e. Poulin and Lefebvre 2002) as well as to favour in general both animal (Meli et al. 2014) and plant (Sebastián-González et al. 2012) biodiversity. Independently on the harvesting practices focused on $P$. australis, it is generally assumed, and further stressed by our results, that the flooding conditions of the reedbed are determinant of their suitability for birds (i.e. Mortelliti et al. 2012; Jedlikowski et al. 2016). As an example, a recent Italian study shows how the 10-years decline of a coastal marshland population of Reed Warbler was associated to the progressive reduction in the flooded portion of the studied reedbeds (Pollo et al. 2018). Analogously, the Reed Warbler suspended reproduction in a wide inland wetland of central Spain as a consequence of a three-years drought and only recovered the initial population size four years after the restoration of the original water level(Jiménez et al. 2018).

These findings claim for the incorporation of a carefully reasoned management of reedbeds within the management plans of all the 'Natura 2000' sites encompassing inland wetlands. These measures should be especially aimed at maintaining permanently flooded the widest possible proportion of the reedbed, and possibly at preserving the variety of micro-habitat within the principal reedbed patches (Jedlikowski et al. 2016). Unfortunately, since $P$. australis reedbeds are excluded from the list of the 'habitats of priority conservation concern' (see above), management plans of Natura 2000 sites are not forced to implement measures aimed at its conservation. However, the faunistic importance of reedbeds (when in a good conservation status) should be highlighted: reedbeds offer equal or even higher availability of suitable habitat for many animal species than the priority habitats that normally occur in inland wetlands of our study area (e.g. Alnus glutionsa forests), and thus they should deserve the right attention in management plans. 


\section{Conclusions}

Our results support the use of multi-species MARS modelling as a tool to analyse factors affecting occurrence in a set of species sharing a common environment but showing a wide range of prevalence among sites. Our findings indicate that, to preserve suitable habitat for the most exigent wetland species, it is recommended to maintain wetlands with wide extension ( $>150$ ha) of flooded transitional wetland habitats (as the 'reedbed/mires' can be considered). These indications should be considered by managers of Natura 2000 sites, and especially of largest sites, where preserving a sufficient overall extension of this habitat type within each site should be regarded as a conservation priority. At a finer scale, the maintenance of patches of reedbeds of at least 2 ha of extension, interspersed with patches of open water, would ensure the most suitable conditions for representative wetland bird species. Above all, the flooding status of the reedbeds acts as a key factor for birds breeding in the wetlands of the pre-Alpine belt. Future conservation actions should be targeted at a landscape instead of an individualwetland perspective (i.e. Whited et al. 2000; Van Meter and Basu 2015) and would pay most of the attention in maintaining wide extent of flooded reedbeds in the 'wetlandscapes' (sensu Thorslund et al. 2017) of this biogeographical region.

\section{Additional file}

Additional file 1: Table S1. Complete list of the 52 original land use/land cover (LULC) types as reported in the DUSAF digital cartography (Lombardy Region 2017) and correspondence to the 9 final Habitat Categories considered for the analyses.

\section{Authors' contributions}

M. Morganti conceived the research project. M. Morganti, M. Manica, VP, PT realized the field work; $\mathrm{MB}$ contribute in analysing data and was a major contributor in writing the manuscript. FL, MG, and GB contributed in writing the manuscript. All authors read and approved the final manuscript.

\section{Author details}

${ }^{1}$ Department of Earth and Environmental Sciences, University of Pavia, Via A, Ferrata 9, 27100 Pavia, Italy. ${ }^{2}$ Conservation Department, Lipu/BirdLife Italy, Via Udine 3/a, 43122 Parma, Italy. ${ }^{3}$ Riserva Naturale 'Torbiere del Sebino', Via Europa 5, 25050 Provaglio d'Iseo, Brescia, Italy. ${ }^{4}$ Riserva Naturale Regionale 'Lago di Piano', Casa della Riserva, Via Statale 1561/d, Frazione Piano Porlezza, Carlazzo, Como, Italy. ${ }^{5}$ Fondazione Lombardia per l'Ambiente, Settore Biodiversità ed Aree Protette, Largo 10 Luglio 1976, 1, 20822 Seveso, MB, Italy. ${ }^{6}$ MUSE, Museo delle Scienze, Sezione di Zoologia dei Vertebrati, Corso del Lavoro e della Scienza, 3, 38122 Trento, Italy. ${ }^{7}$ Present Address: Department of Environmental Science and Policy, University of Milan, Via Celoria 26, 20133 Milan, Italy.

\section{Acknowledgements}

We acknowledge for support in the survey organization and realization: Mariella Nicastro (Regional Park'Valle Lambro'); Daniele Vezzoli, Emanuele Forlani and Stefania Capelli (Gruppo Ricerche Avifauna-Brescia); the administration of Nature Reserves 'Pian di Spagna' and 'Lago di Piano'; the staff of the
LIPU-Birdlife section of 'Palude Brabbia'; all the members of the association 'Centro Ricerche Ornitologiche Scanagatta-Varenna'.

\section{Funding}

This project was realized in the framework of the Actions A.11 and D.3LIFE14 IPE IT 018 GESTIRE 2020_Nature Integrated Management to 2020. MM is currently a post-doc at the University of Milan, funded by LIFE FALKON LIFE17 NAT/IT/000586.

\section{Availability of data and materials}

The datasets used and/or analysed during the current study are available from the corresponding author on reasonable request.

\section{Competing interests}

The authors declare that they have no competing interests.

\section{Consent for publication}

Not applicable.

\section{Ethics approval and consent to participate}

Not applicable.

Received: 9 October 2018 Accepted: 21 April 2019

Published online: 01 May 2019

\section{References}

Almaraz P, Amat JA. Multi-annual spatial and numeric dynamics of the whiteheaded duck Oxyura leucocephala in southern Europe: seasonality, density-dependence and climatic variability. J Anim Ecol. 2004;73:1013-23.

Amat JA, Green AJ. Waterbirds as bioindicators of environmental conditions. In: Hurford C, Schneider M, Cowx I, editors. Conservation monitoring in freshwater habitats. Dordrecht: Springer; 2010. p. 45-52.

Assandri G, Bogliani G, Pedrini P, Brambilla M. Land-use and bird occurrence at the urban margins in the Italian Alps: implications for planning and conservation. Northwest J Zool. 2017;13:77-84.

Barbraud C, Lepley M, Mathevet R, Mauchamp A. Reedbed selection and colony size of breeding Purple Herons Ardea purpurea in southern France. Ibis. 2002;144:227-35

Beemster N, Troost E, Platteeuw M. Early succesional stages of Reed Phragmites australis vegetations and its importance for the Bearded Reedling Panurus biarmicus in Oostvaardersplassen, The Netherlands. Ardea. 2010:98:339-54.

Brambilla M, Jenkins RK. Cost-effective estimates of water rail Rallus aquaticus breeding population size. Ardeola. 2009:56:95-102.

Brambilla M, Fulco E, Gustin M, Celada C. Habitat preferences of the threatened Black-eared Wheatear Oenanthe hispanica in southern Italy. Bird Study. 2013;60:432-5.

Brambilla M, Gobbi M. A century of chasing the ice: delayed colonisation of ice-free sites by ground beetles along glacier forelands in the Alps. Ecography. 2014;37:33-42.

Brambilla M, Pedrini P. Modelling at the edge: habitat types driving the occurrence of common forest bird species at the altitudinal marging of their range. Ornis Fenn. 2016:93:88-99.

Brambilla M, Rubolini D. Water Rail Rallus aquaticus breeding density and habitat preferences in northern Italy. Ardea. 2004;92:11-7.

Burger J, Eichhorst B. Heavy metals and selenium in grebe eggs from Agassiz National Wildlife Refuge in northern Minnesota. Environ Monitor Assess. 2005; 107:285-95

Cable TT, Brack V, Holmes V. Simplified method for wetland habitat assessment. Environ Manage. 1989;13:207-13.

Celada C, Bogliani G. Breeding bird communities in fragmented wetlands. Boll Zool. 1993;60:73-80.

Ceresa F, Belda EJ, Gómez J, Miñana IJ, Soler L, Villaroya J, Monrós JS. Differences in time and space use between two sympatric Acrocephalus warblers with similar diet. Bird Study. 2016;63:172-80.

Coops $\mathrm{H}$, van der Velde $\mathrm{G}$. Seed dispersal, germination and seedling growth of six helophyte species in relation to water level zonation. Freshw Biol. 1995;34:13-20. 
Cramp S, Simmons K. The complete birds of the Western Palearctic on CDROM. Oxford: Oxford University Press; 1998.

DUSAF. Shapefile of region Lombardy (Italy) land uses. v5.0. 2015. http://www. geoportale.regione.lombardia.it.

Elith J, Leathwick J. Predicting species distributions from museum and herbarium records using multiresponse models fitted with multivariate adaptive regression splines. Divers Distrib. 2007;13:265-75.

Fasola M, Rubolini D, Merli E, Boncompagni E, Bressan U. Long-term trends of heron and egret populations in Italy, and the effects of climate, humaninduced mortality, and habitat on population dynamics. Popul Ecol. 2010;52:59.

Fér T, Hroudová Z. Genetic diversity and dispersal of Phragmites australis in a small river system. Aquat Bot. 2009;90:165-71.

FLA (Fondazione Lombardia per I'Ambiente). Programma di monitoraggio scientifico della Rete Natura 2000 in Lombardia. Parte 1: Fauna. Technical report of LIFE11 NAT/IT/000044 'Gestire'-Action D1. 2015.

Friedman JH. Multivariate adaptive regression splines. Ann Stat. 1991;19:1-67.

Gardner RC, Barchiesi S, Beltrame C, Finlayson C, Galewski T, Harrison I, Paganini M, Perennou C, Pritchard D, Rosenqvist A, Walpole M. State of the world's wetlands and their services to people: a compilation of recent analyses (March 31, 2015). Ramsar Briefing Note No. 7. Gland, Switzerland: Ramsar Convention Secretariat; 2015.

Garg A, Tai K. Comparison of statistical and machine learning methods in modelling of data with multicollinearity. Int J Model Identif Control. 2013;18:295-312.

Gray MJ, Hagy HM, Nyman JA, Stafford JD. Chapter 4-management of wetlands for wildlife. In: Anderson JT, Davis CA, editors. Wetland techniques: Volume 3: Applications and management. USGS Staff-Published Research. 803. 2013. p. 121-80. http://digitalcommons.unl.edu/usgsstaffp ub/803.

Guareschi S, Abellan P, Laini A, Green AJ, Sanchez-Zapata JA, Velasco J, Millan A. Cross-taxon congruence in wetlands: assessing the value of waterbirds as surrogates of macroinvertebrate biodiversity in Mediterranean Ramsar sites. Ecol Indic. 2015;49:204-15.

Hastie T, Tibshirani R, Friedman J. The elements of statistical learning: data mining, inference, and prediction. New York: Springer; 2009.

Heinanen S, von Numers M. Modelling species distribution in complex environments: an evaluation of predictive ability and reliability in five shorebird species. Divers Distrib. 2009;15:266-79.

ISTAT. Istituto Nazionale di Statistica. http://dati.istat.it/Index.aspx?Query Id =18460. 2018. Accessed 31 Aug 2018.

Jedlikowski J, Brambilla M, Suska-Malawska M. Fine-scale selection of nesting habitat in Little Crake Porzana parva and Water Rail Rallus aquaticus in small ponds. Bird Study. 2014;61:171-81.

Jedlikowski J, Chibowski P, Karasek T, Brambilla M. Multi-scale habitat selection in highly territorial bird species: exploring the contribution of nest, territory and landscape levels to site choice in breeding rallids (Aves: Rallidae). Acta Oecol. 2016;73:10-20.

Jiménez J, Hernandez JM, Feliu J. Breeding in a dry wetland. Demographic response to drought in the common reed-warbler Acrocephalus scirpaceus. Ardeola. 2018;65:247-59.

Kennerley P, Pearson D. Reed and bush warblers. London: Christopher Helm Publishers Ltd.; 2010.

Leathwick JR, Elith J, Hastie T. Comparative performance of generalized additive models and multivariate adaptive regression splines for statistical modelling of species distributions. Ecol Model. 2006;199:188-96.

Leu M, Farnsworth ML, Fleishman E, Dobkin DS, Scherer RD, Noon BR, Dickson BG. Effects of point-count duration on estimated detection probabilities and occupancy of breeding birds. J Field Ornithol. 2017;88:80-93.

Martínez-Fernández J, Esteve-Selma MA, Robledano-Aymerich F, Pardo-Sáez MT, Carreño-Fructuoso MF. Aquatic birds as bioindicators of trophic changes and ecosystem deterioration in the Mar Menor lagoon (SE Spain). Hydrobiologia. 2005;550:221-35.

Matsinos YG, Wolf WF. An individual-oriented model for ecological risk assessment of wading birds. Ecol Model. 2003;170:471-8.

Meli P, Rey-Benayas JM, Balvanera P, Martinez-Ramos M. Restoration enhances wetland biodiversity and ecosystem service supply, but results are context-dependent: a meta-analysis. PLoS ONE. 2014;9:e93507.

Merkel A. http://www.it.climate-data.org. Accessed on 12 Sept 2017.
Méro TO, Zuljevic A, Varga K, Lengyel S. Wing size-related reed habitat selection by Great Reed Warblers (Acrocephalus arundinaceus) males. Auk. 2017:133:205-12.

Méro TO, Zuljevic A, Varga K, Lengyel S. Reed management infuences philopatry to reed habitats in the Great Reed Warbler (Acrocephalus arundinaceus). Condor. 2018;120:94-105.

Milborrow S. Package'earth' 3.2-1. Multivariate adaptive regression spline models. 2011 a. http://cran.r-project.org/web/packages/earth.

Milborrow S. Plotmo: Plot a model's response while varying the values of the predictors. 2011b. http://cran.r-project.org/web/packages/.

Mitsch WJ, Gosselink JG. Wetlands. New York: Wiley; 2000.

Mortelliti A, Sozio G, Boccacci F, Ranchelli E, Cecere JG, Battisti C, Boitani L. Effect of habitat amount, configuration and quality in fragmented landscapes. Acta Oecol. 2012;45:1-7.

Polak M. Temporal pattern of vocal activity of the Water Rail Rallus aquaticus and the Little Crake Porzana parva in the breeding season. Acta Ornithol. 2005;40:21-6.

Pollo R, Muzzati M, Volponi S. Estimation of the demographic parameters of Common Reed Warbler Acrocephalus scirpaceus breeding in three wetlands of central and northern Italy through data of Capture-MarkingRecapture (CRM). Avocetta. 2018;42:21-30.

Poulin B, Lefebvre G. Effect of winter cutting on the passerine breeding assemblage in French Mediterranean reedbeds. Biodivers Conserv. 2002;11:1567-81.

Prigent C, Papa F, Aires F, Jimenez C, Rossow WB, Matthews E. Changes in land surface water dynamics since the 1990s and relation in population pressure. Geoph Res Lett. 2012;39:L08403. https://doi.org/10.1029/2012G L051276.

Quantum GIS Development Team. Quantum GIS Geographic Information System. Open Source Geospatial Foundation Project. 2018. http://www. qgis.org.

R Core Team. R: A language and environment for statistical computing. R Foundation for Statistical Computing, Vienna, Austria. 2018. http:// www.R-project.org.

Ramsar Convention Secretariat. The Ramsar Convention Manual: a guide to the convention on wetlands (Ramsar, Iran, 1971). 4th ed. Gland: Ramsar Convention Secretariat; 2006.

Rendón MA, Green AJ, Aguilera E, Almaraz P. Status, distribution and long-term changes in the waterbird community wintering in Doñana, south-west Spain. Biol Conserv. 2008;141:1371-88.

Russo RE, editor. Wetlands: ecology, conservation and restoration. New York: Nova Science Publisher Inc: 2008

Salmerón Gómez R, García Pérez J, López Martín M, García García C. Collinearity diagnostic applied in ridge estimation through the variance inflation factor. J Appl Stat. 2016;43:1831-49.

Schultze A, Dingler K. The bird songs of Europe, North Africa and the Middle East. Germering: Musikverlag Ample Edition; 2007.

Sebastián-González E, Molina JA, Paracuellos M. Distribution patterns of a marsh vegetation metacommunity in relation to habitat configuration. Aquat Biol. 2012;16:277-85.

Sozio G, Mortelliti A, Boccacci F, Ranchelli F, Battisti C, Boitani L. Conservation of species occupying ephemeral and patchy habitats in agricultural landscapes: the case of the Eurasian reed warbler. Lands Urban Plan. 2012;119:9-19.

Sutherland WJ, Newton I, Green R. Bird ecology and conservation: a handbook of techniques, vol. 1. Oxford: Oxford University Press; 2004.

Thorslund J, Jarsjo J, Jaramillo F, Jawitz JW, Manzoni S, Basu NB, Chalov SR, Cohen MJ, Creed IF, Goldenberg R, Hylin A, Kalantari Z, Koussis AD, Lyon SW, Mazi K, Mard J, Persson K, Pietron J, Prieto C, Quin A, Van Meter K, Destouni G. Wetlands as large-scale nature-based solutions: status and challenges for research, engineering and management. Ecol Eng. 2017:108:489-97.

Trochet A, Schmeller DS. Effectiveness of the Natura 2000 network to cover threatened species. Nat Conserv. 2013;4:35-53.

Tscharntke T. Fragmentation of phragmites habitats, minimum viable population size, habitat suitability, and local extinction of moths, midges, flies, aphids, and birds. Conserv Biol. 1992;6:530-6.

Van Meter KJ, Basu NB. Signatures of human impact: size distribution and spatial organization of wetlands in the Prairie Pothole landscape. Ecol Appl. 2015;25:451-65. 
Wang X, Kuang F, Tan K, Ma Z. Population trends, threats, and conservation recommendations for waterbids in China. Avian Res. 2018;9:14.

Ward DB, Jacono CC. Phragmites australis (Common Reed), a looming threat to Florida wetlands. Wildland Weeds. 2009;12:7-9.

Wetlands International. Waterbird population estimates. 2018. http://wpe. wetlands.org. Accessed 4 Sept 2018.

Weller MW. Freshwater marshes: ecology and wildlife management. Minneapolis: University of Minnesota Press; 1994.
Whited D, Galatowitsch S, Tester JR, Schik K, Lehtinen R, Husveth J. The importance of local and regional factors in predicting effective conservation planning strategies for wetland bird communities in agricultural and urban landscapes. Land Urban Plan. 2000;49:49-65.

Zedler JB, Kercher S. Wetland resources: status, trends, ecosystem services, and restorability. Annu Rev Environ Resour. 2005;30:39-74.
Ready to submit your research? Choose BMC and benefit from:

- fast, convenient online submission

- thorough peer review by experienced researchers in your field

- rapid publication on acceptance

- support for research data, including large and complex data types

- gold Open Access which fosters wider collaboration and increased citations

- maximum visibility for your research: over $100 \mathrm{M}$ website views per year

At BMC, research is always in progress.

Learn more biomedcentral.com/submissions 